\title{
Simplified Mechanical Model of Ship Lift-Ship Box Structure
}

\author{
Yan $\mathrm{Li}^{1, \mathrm{a}^{*}}$ \\ ${ }^{1}$ Institute of Transportation Engineering, Wuhan Technical College of Communications, Wuhan \\ 430065, China \\ a284837747@qq.com
}

\begin{abstract}
Keywords: Three Gorges Ship Lift. Ship box. Gear-rack climbing type. Simplified mechanical model.
\end{abstract}

Abstract. According to the connection feature of the gear and rack, an equivalent two-dimensional tandem and many freedom-degrees dynamic model of the structure system including the ship lift and the ship box was established based on the dynamic characteristics of three-dimensional finite element model. The results indicate that the simplified model can represent preferably the dynamic characteristics of the structural system, which can be used in seismic response analysis on the coupled system consisted of the ship lift, the ship box and water in box.

\section{Introduction}

By repeated type selection research, the Three Gorges Ship lift was determined to be gear-rack climbing type instead of the original wire rope hoisting type[1]. The relatively independent connection form between tower and ship box was changed into close contact. Under earthquake action, the ship box and water in it will shake following the ship lift pillar and water sloshing will affect the seismic response of ship lift main structure in turn. And then the ship lift structure, ship box and water form a fluid-solid coupling system. It is unrealistic to do dynamic calculation of the coupling system directly. It is necessary to establish a simplified mechanical model of the coupling system. There were some studies on establishing the simplified mechanical model of ship lift, but they did not talk about the correlation of ship lift pillar and ship box[2,3]. Some research showed that there was no inclination flips between gear and rack of the vertical climbing system[4]. So if the horizontal displacement between the gear and the rack is neglected and the vertical takeoff and landing movement is separated into various working conditions, there is no relative displacement between the ship box and the ship lift pillar in each condition. In this paper, an equivalent two-dimensional tandem and many freedom-degrees simplified dynamic model of the ship lift main structure-ship box system was founded based on the three-dimensional finite element model according to the characteristics of the gear and rack connection form. Only the condition when ship box was on the top of the pillar was considered to be as a typical working condition.

\section{Three-dimensional Finite Element Model of the Ship Lift-Ship Box Structure}

The Three Gorges Ship Lift is composed of four giant symmetrical reinforced concrete pillars which support a big span machine room at the top with total height of 160 meters and pillar height of 136 meters. The concrete slab thickness is 2.5 meters at the top of pillar. All the rest floor thickness is 0.5 meters. The shape size of ship box is $132 \mathrm{~m} \times 23.4 \mathrm{~m} \times 10 \mathrm{~m}$. The three-dimensional finite element model was established by ANSYS for half of the Three Gorges Ship Lift as shown in Fig.1. The pillar cylinder, the machine room roof at the top, all floors and ship box were defined as Shen63 elastic shell element. The lateral structure of the machine room was defined as Beam 4 elastic beam element. The elastic modulus value of ship box shell element was assumed to be $3000 \mathrm{GPa}$ due to its very big stiffness. The thickness of the ship box shell element was calculated according to quality equivalent.

ANSYS modal analysis results show that the first vibration mode is overall translation in $Y$ direction and the following eight vibration modes are all local vibration of machine room at the top of ship lift. Among them, the sixth and eighth vibration modes are torsion of the machine room. The first eight natural vibration frequencies and vibration modes of finite element model are shown in Table2. 


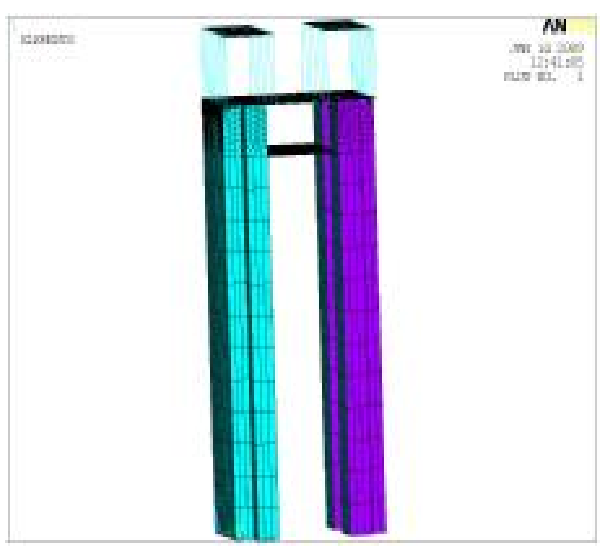

Fig. 1. Three-dimensional finite element model

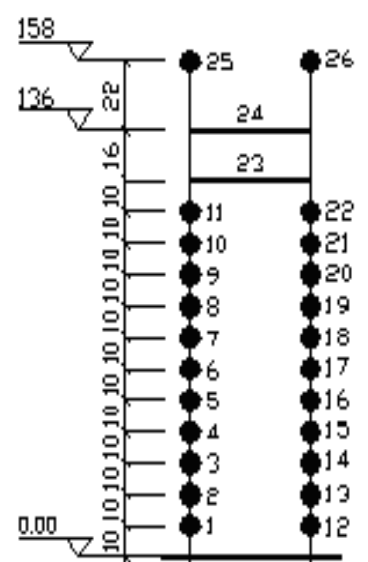

Fig. 2. Simplified mechanical model

\section{Simplified Mechanical Model of the Ship Lift-Ship Box Structure}

Assumption. Three-dimensional finite element model was condensed to be two-dimensional simplified model more degrees of freedom using the lumped mass method. In addition to maintain the linear elastic hypothesis of the structure, the following assumptions were also adopted:

(1) The whole quality of floor was focused on node layer.

(2)The in-plane stiffness of floor was infinite under flat section assumption.

The two-dimensional tandem and many freedom-degrees dynamic model of the ship lift-ship box system was shown in Fig.2.

Mass matrix. The mass matrix of the simplified model was $26 \times 26$ diagonal matrix. The diagonal coefficient value as shown in table 1 was the total condensed mass of each floor.

Table 1 Concentrated mass of note layers of the simplified mechanical model [kt]

\begin{tabular}{cccccccccccccccc}
\hline $\begin{array}{c}\text { note } \\
\text { mass }\end{array}$ & mass & note & mass & \multicolumn{1}{c}{ note mass } & note mass & note mass & note mass & note \\
\hline 1 & 5.492 & 2 & 5.492 & 3 & 5.492 & 4 & 5.492 & 5 & 5.492 & 6 & 5.492 & 7 & 5.492 \\
8 & 5.492 & 9 & 5.492 & 10 & 5.492 & 11 & 5.492 & 12 & 5.492 & 13 & 5.492 & 14 & 5.492 \\
15 & 5.492 & 16 & 5.492 & 17 & 5.492 & 18 & 5.492 & 19 & 5.492 & 20 & 5.492 & 21 & 5.492 \\
22 & 5.492 & 23 & 16.78 & 24 & 21.99 & 25 & 3.427 & 26 & 3.427 & & & & \\
\hline
\end{tabular}

Lateral stiffness matrix. The solution process of the stiffness matrix of the simplified model was as follows [2]:

(1) The total horizontal force of unit 1 was applied on all nodes of $i(i=1,2,3 \ldots)$ note layer of the three-dimensional finite element model;

(2) The note average displacement of $j(j=1,2,3 \ldots)$ note layer of the three-dimensional finite element model was calculated to obtain flexibility coefficient $\delta_{i j}(i, j=1,2,3 \ldots)$;

(3) The flexibility coefficient $\delta_{i j}(i, j=1,2,3 \ldots)$ was integrated into flexibility matrix $\delta$;

(4) The stiffness matrix $K$ was the inverse flexibility matrix, $K=\delta^{-1}$.

Damping Matrix. The frequently-used Rayleigh damping was adopted. That's:

$$
C=\lambda_{1} M+\lambda_{2} K
$$

where $\lambda_{1}=2 \omega_{1} \omega_{2}\left(\zeta_{1} \omega_{2}-\zeta_{2} \omega_{1}\right) /\left(\omega_{2}^{2}-\omega_{1}^{2}\right), \lambda_{2}=2\left(\zeta_{1} \omega_{2}-\zeta_{2} \omega_{1}\right) /\left(\omega_{2}^{2}-\omega_{1}^{2}\right) . \omega_{1}$ and $\omega_{2}$ were the first and the second order natural vibration frequency. $\zeta_{1}$ and $\zeta_{2}$ were damping ratio which were both assigned 0.05 for the ship lift structure. So there were equations $\lambda_{1}=0.1 \omega_{1} \omega_{2} /\left(\omega_{1}+\omega_{2}\right), \lambda_{2}=0.1 / \omega_{1}+\omega_{2}$. 
Dynamic Characteristics of Simplified Model. The free vibration equation of the simplified model was:

$$
K x(t)+M(t)=0
$$

where $K$ was the stiffness matrix, $M$ is the mass matrix.

The node layers were assumed to do harmonic vibration:

$$
x(t)=\Delta \sin (\omega t+\phi)
$$

where $\Delta$ was the displacement amplitude vector. The following equation can be obtained by (2) and (3):

$$
\left(K-\omega^{2} M\right) \Delta=0
$$

Then the general characteristic equation was given as:

$$
\left|K-\omega^{2} M\right|=0
$$

The natural vibration frequency of the simplified model can be gained by solving the above characteristic equation. The comparison analysis on first eight natural vibration frequencies of the simplified model and the three-dimensional finite element model was conducted as shown in Table 2. It's obviously that error margins were all less than 5\%. So the dynamic characteristics of the simplified mechanical model and the three dimensional finite element model are equivalent.

Table 2 First eight natural vibration frequencies of finite element model and simplified model $(\mathrm{Hz})$

\begin{tabular}{lccccrrrr}
\hline Vibration mode & $1(\mathrm{Y})$ & $2(\mathrm{X})$ & $3(\mathrm{X})$ & $4(\mathrm{Y})$ & $5(\mathrm{Y})$ & $6(\mathrm{~T})$ & $7(\mathrm{Y})$ & $8(\mathrm{~T})$ \\
\hline finite element model & 0.4493 & 0.7724 & 0.8127 & 1.2345 & 1.2386 & 1.2788 & 1.3185 & 1.3599 \\
simplified model & 0.4596 & 0.7884 & 0.8501 & 1.1863 & 1.2039 & 1.2409 & 1.2879 & 1.3008 \\
error margin & $2.24 \%$ & $2.03 \%$ & $4.40 \%$ & $3.90 \%$ & $2.80 \%$ & $2.96 \%$ & $2.32 \%$ & $4.35 \%$ \\
\hline
\end{tabular}

\section{Structural seismic response analysis}

The basic intensity is 6 degrees in the three gorges project site where the seismic fortification intensity is 7 degrees. The three gorges simulating seismic wave was selected as shown in Fig.3. In order to do contrast analysis, the acceleration amplitude was in proportion to increase to $4.0 \mathrm{~m} / \mathrm{s} 2$.which was amount to the peak acceleration in 9 degrees seismic fortification intensity.

For the simplified mechanical model, under the earthquake action in machine room bent direction in which direction the lateral stiffness of the ship lift structure is smaller, the equation of motion of the ship lift structure is as follows:

$$
[M]\{+[C]\{\&+[K]\{y\}=-[M][I](t)
$$

where $[M],[C],[K]$ are respectively mass matrix, damping matrix and stiffness matrix. $\{y\} 、\{q$ 、 $\{$ are displacement, velocity and acceleration vector of each note later to take the ground as reference. $[I]$ is the unit column vector.

The equation 6 was solved by Newmark - $\beta$ step integral method to obtain seismic response of all the note layers of the simplified model. In order to further illustrate the effectiveness of the ship lift structure simplified mechanics model, the displacement response of simplified mechanical model were compared with the displacement response of finite element model as shown in Fig.4. The 25 
note layer maximal displacement response of the simplified model and the finite element model was $74.1 \mathrm{~mm}$ and $76.8 \mathrm{~mm}$ respectively. The 24 note layer maximal displacement response of the simplified model and the finite element model was $57.2 \mathrm{~mm}$ and $56.0 \mathrm{~mm}$ respectively. The difference of the maximum displacement value of two models were all less than $5 \%$ which further indicated that the ship lift simplified mechanics model is effective.

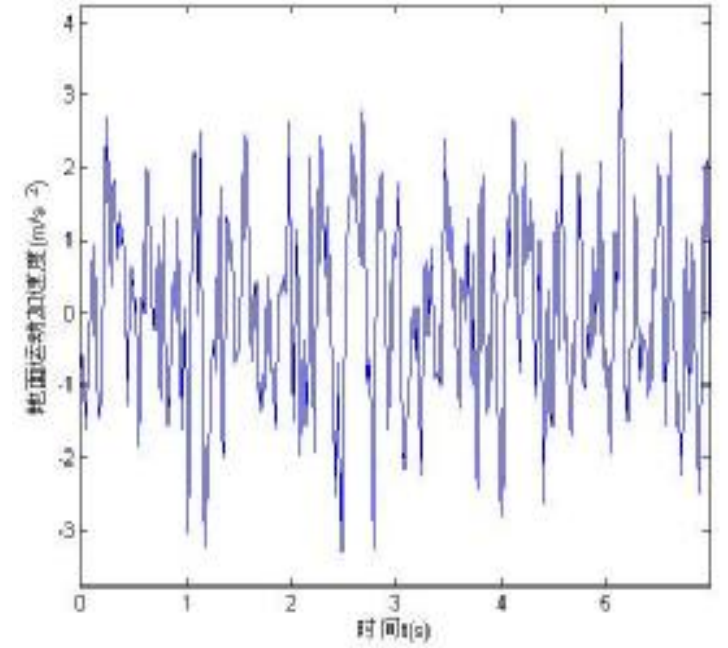

Fig. 3. The three gorges simulating seismic wave note layers

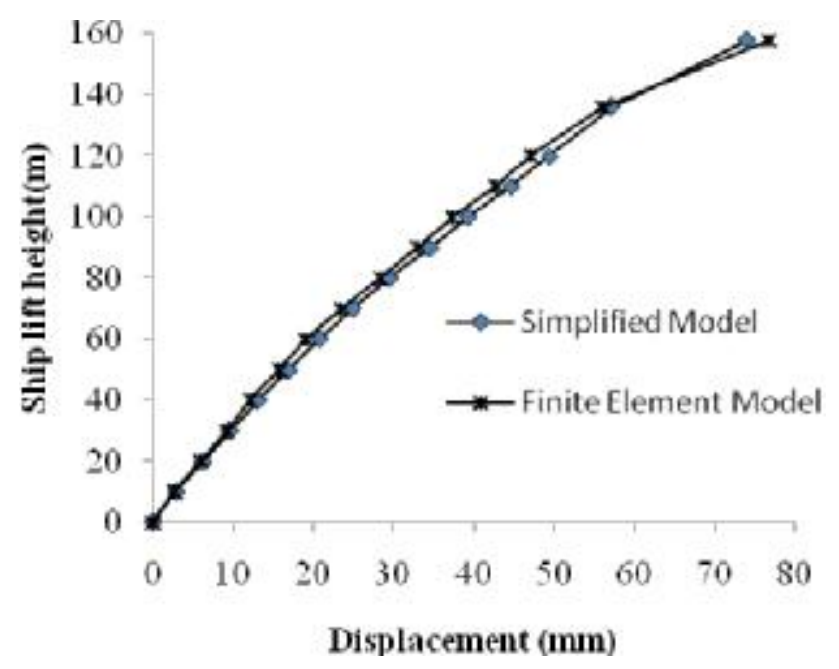

Fig. 4. Maximal displacement of all ship lift

\section{Summary}

a. The dynamic characteristics of the simplified mechanical model is equal to the finite element model, the simplified model is effective.

b. The simplified mechanical model can represent preferably the seismic response of the ship lift. It can be used in seismic response analysis on the coupled system including the ship lift main structure, ship box and water in it.

\section{Acknowledgement}

This work has financially been supported by the Hubei Province Scientific and Technological Research Project (B2014205).

\section{References}

[1] Wang Yuanhua. Three Gorges Ship Lift stereotypia[N]. The china's three gorges project. (in chinese)

[2] Lu Mingwei, Qu Weilian, Chen Wei, Simplified mechanical model of lift-ship structure for earthquake response based on finite element model $[\mathrm{J}]$. Journal of Wuhan University of Technology, 2002,24(5):55-57.(in chinese)

[3] Qu Weilian, Zhou Yao. Reduced Mechanical mode of Three-Gorges Lift-ship structure[J]. J. of HUST. (Urban Science Edition), 2003.20(4):1-3. (in chinese)

[4] Yu Yongsheng, Gong Manfeng. On eigenvibration behavior of ship lift combining structures with lifting steel rope in complete equilibrium[J]. Chinese Journal of Computational Mechanics,2003,20(5):568-573. (in chinese) 